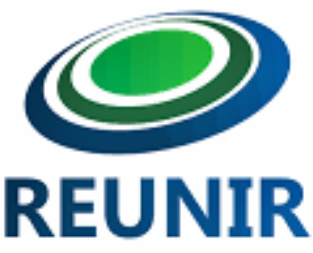

REUNIR:

Revista de Administração,

Ciências Contábeis e

Sustentabilidade

www.reunir.revistas.ufcg.edu.br

ARTIGO ORIGINAL

\title{
Ética na Administração Pública: uma Análise da Percepção da Comunidade Universitária do Centro de Ciências Biológicas e da Saúde da Universidade Federal de Campina Grande ${ }^{1}$
}

\section{Ethics in Public Administration: an Analysis of the Perception of the University Community of the Center of Biological Sciences and Health of the Federal University of Campina Grande}

\section{Ética en la Administración Pública: un Análisis de la Percepción de la Comunidad Universitaria del Centro de Ciencias Biológicas y de la Salud de la Universidad Federal de Campina Grande}

\author{
Bruno de Araujo Azevedo², Erivaldo Moreira Barbosa ${ }^{3}$, Maria de Fátima Nóbrega Barbosa ${ }^{4}$
}

\section{PALAVRAS-CHAVE Administração Pública. Código de Ética. Percepção positiva.}

\begin{abstract}
Resumo:
Discussões éticas estão presentes em praticamente todos os aspectos da vida humana. $\mathrm{Na}$ Administração Pública, são cada vez mais frequentes, em razão da inversão de valores que está posta, na qual os interesses particulares parecem se sobrepor à busca pelo bem comum. Nesse contexto, a presente pesquisa teve como objetivo, analisar a percepção da comunidade universitária do Centro de Ciências Biológicas e da Saúde, da Universidade Federal de Campina Grande, acerca da ética na Administração Pública. Tratou-se de uma pesquisa de campo do tipo exploratório-descritiva, valendo-se do método indutivo, utilizando como sujeitos da pesquisa, as pessoas que compõem o órgão objeto do estudo. Os resultados da pesquisa indicaram uma percepção positiva da população estudada acerca da prestação do serviço público no Centro, bem como a adequação da conduta dos servidores às normas éticas, muito embora tenham revelado um baixo índice de conhecimento acerca do Código de Ética da profissão e da Comissão de Ética setorial. Ao final, foram apresentadas proposições, visando à promoção da ética, como por exemplo, a elaboração e distribuição de uma cartilha educativa,
\end{abstract}

\footnotetext{
${ }^{1}$ Submetido em: 30/01/2019. Aceite: 19/02/2020. Publicado: 15.04.2020. Responsável: Universidade Federal de Campina Grande/UACC/PROFIAP/CCJS/UFCG

2 ID ORCID: https://orcid.org/0000-0002-6215-5281. Mestre em Administração Pública pelo PROFIAP, Bacharel em Direito pela UEPB, e-mail: bruno8809@gmail.com

3 ID ORCID: http.s://orcid.org/0000 - 0001- 7479 - 1827. Professor da UAD/UFCG e do PROFIAP/UFCG, e-mail: erifat@terra.com.br.

4 ID ORCID: https: //orcid.org/0000 - 0003 - 3415 - 8829. Professora da UACC/UFCG e do PROFIAP/UFCG, e-mail:

mfnobregabarbosa@gmail.com.
}

REUNIR: Revista de Administração, Contabilidade e Sustentabilidade

ISBN: 2237-3667, 10(1), 2020. 


\section{KEYWORDS}

Public Administration. Code of Ethics. Positive perception.

\section{PALABRAS CLAVE}

Administracion Publica. Código de Ética.

Percepción positiva. realização de seminários abordando a ética na Administração Pública e a criação de uma normatização interna de conduta ética na instituição.

\section{Abstract:}

Ethical discussions are present in virtually every aspect of human life. In Public Administration, they are increasingly frequent, because of the inversion of values that is set, in which private interests seem to overlap with the search for the common good. In this context, the present research had the objective of analyzing the perception of the university community of the Center of Biological Sciences and Health, Federal University of Campina Grande, about ethics in Public Administration. It was an exploratory-descriptive field research, using the inductive method, using as subjects of the research, the people that make up the organ object of the study. The results of the research indicated a positive perception of the population studied regarding the provision of the public service in the Center, as well as the adequacy of the servers' conduct to ethical standards, even though they revealed a low index of knowledge about the Code of Ethics of the profession and Ethics Committee. In the end, propositions were presented to promote ethics in the University, such as the elaboration and distribution of an educational booklet, seminars on ethics in public administration and the creation of an internal standard of ethical conduct in the institution.

\section{Resumen:}

Las discusiones éticas están presentes en prácticamente todos los aspectos de la vida humana. En la Administración Pública, son cada vez más frecuentes, en razón de la inversión de valores que está puesta, en la cual los intereses particulares parecen superponerse a la búsqueda del bien común. En este contexto, la presente investigación tuvo como objetivo, analizar la percepción de la comunidad universitaria del Centro de Ciencias Biológicas y de la Salud, de la Universidad Federal de Campina Grande, acerca de la ética en la Administración Pública. Se trata de una investigación de campo del tipo exploratorio-descriptivo, valiéndose del método inductivo, utilizando como sujetos de la investigación, las personas que componen el órgano objeto del estudio. Los resultados de la investigación indicaron una percepción positiva de la población estudiada acerca de la prestación del servicio público en el Centro, así como la adecuación de la conducta de los servidores a las normas éticas, aunque revelaron un bajo índice de conocimiento acerca del Código de Ética de la profesión y la Comisión de Ética sectorial. Al final, se presentaron proposiciones, buscando la promoción de la ética en la Universidad, como por ejemplo, la elaboración y distribución de una cartilla educativa, realización de seminarios abordando la ética en la Administración Pública y la creación de una normatización interna de conducta ética en la institución. 


\section{Introdução}

As discussões sobre a ética têm sido gradativamente percebidas em praticamente todos os aspectos da vida humana na atualidade. Por se tratar de um tema extremamente amplo, todas as situações, desde as mais simples até as mais complexas relações humanas, podem ser observadas sob o ponto de vista da moralidade em suas condutas.

A conduta ética pressupõe a prática de uma ação alicerçada nos valores e princípios que promovam o bem comum. 0 que significa que sobre o indivíduo é gerado um sentimento de dever incondicional, o chamado imperativo categórico, que o impele à prática do ato tendo consciência de que sua ação terá influência sobre a coletividade e, consequentemente, sobre si mesmo (Kant, 1993).

Quando estudada dentro da Administração Pública, a ética está fortemente ligada à relação existente entre Estado e sociedade, ou seja, do sentimento público de cidadania. 0 que pressupõe a sensação de pertencimento a um lugar, no qual o indivíduo tem liberdade para agir de acordo com seu próprio arbítrio, mas ao mesmo tempo está subordinado a uma normatividade isonômica (MatiasPereira, 2013).

0 interesse da sociedade e da academia no tema tem crescido sobremaneira, pois a conduta antiética, não só compromete a capacidade de governança como também representa um risco considerável para a própria sobrevivência de organizações privadas, da Administração Pública e do Estado de Direito (Matias-Pereira, 2013).

A ética pode ser analisada sob dois pontos de vista distintos: filosofia da moral e conjunto de princípios. No primeiro caso, de herança aristotélica, a ética pode ser classificada como um pensamento reflexivo sobre valores e regras que regem a conduta humana. É o que o autor denomina ética teleológica. No segundo, de herança kantiana, a ética pode ser classificada como um conjunto de princípios e regras que um grupo específico estabelece para a sua prática profissional, a exemplo dos códigos de ética das profissões. Essa última, denominada ética deontológica (Ricoeur, 1991).

É nesse contexto que surge no Brasil, em 1994, o Código de Ética Profissional do Servidor Público Civil do Poder Executivo Federal, através do Decreto $n^{\circ} 1.171 / 94$, que contempla substancialmente os princípios morais e éticos a serem observados pelo servidor, independente da especificidade profissional, e formalmente regula a criação e funcionamento das Comissões de Ética em todos os órgão e entidades da Administração Pública Federal.

A Exposição de Motivos do Código afirma que sua existência é imprescindível, em especial num momento em que os casos de corrupção generalizada são estimulados pela impunidade, bem como pela ausência de valores morais e éticos, ressaltando que o arcabouço jurídico brasileiro se mostra ineficiente na correção das anomalias de conduta.

0 presente estudo realizou uma análise, com base nas teorias da percepção, da ética e da moral, bem como nos estudos relacionados à Administração Pública, tomando como amostra os três segmentos que compõem o Centro de Ciências Biológicas e da Saúde (CCBS), da Universidade
Federal de Campina Grande (UFCG), discentes, docentes e servidores técnico-administrativos, fazendo a seguinte indagação: Qual a percepção da comunidade universitária do Centro de Ciências Biológicas e da Saúde, da Universidade Federal de Campina Grande, sobre a ética na Administração Pública?

Considerando que tanto se fala na sociedade atual, sobre uma possível crise ética vivenciada atualmente no Brasil, especialmente nas instituições públicas, o presente estudo, utilizando uma abordagem interdisciplinar, teve como objetivo: analisar a percepção da comunidade universitária do CCBS da UFCG, acerca da ética na Administração Pública.

A pesquisa aqui realizada poderá contribuir de forma expressiva para a promoção do Código de Ética Profissional do Servidor Público Civil do Poder Executivo Federal, incentivando o seu cumprimento não só no âmbito do CCBS, mas de toda a UFCG, o que melhorará sobremaneira sua imagem perante a sociedade.

Consoante à publicidade que foi dada às questões éticas, a partir da elaboração e publicação do Código de Ética, convenientemente, o presente estudo fortalece as discussões sobre o assunto, fazendo com que cada indivíduo que obtenha contato com esta pesquisa, seja dela participante ou leitor, seja conduzido a uma reflexão sobre as questões morais.

Ressalte-se que, mesmo que indiretamente, a própria Administração Pública é beneficiada pela execução deste trabalho, pois, considerando que em um Estado Democrático de Direito, cada cidadão tem uma parcela de responsabilidade na busca por uma sociedade fraterna, pluralista e sem preconceitos, à medida que se dissemina a prática da ética, mesmo que em pequena escala, mudanças culturais positivas poderão ser observadas.

\section{Elementos teóricos da pesquisa}

\section{Ética e moral}

Uma grande expansão acerca do debate ético pôde ser observada nos últimos anos, na sociedade e em torno das instituições em geral. Em meio à crise política que assola o país, cada vez mais se têm intensificado as discussões sobre a carência de conduta ética e moralidade, sobretudo na administração pública.

Importante ressaltar que uma definição de moralidade, simples e incontestável, seria impossível. 0 que há são diversas teorias divergentes, cada uma apresentando uma definição ao termo. Destarte, é comum que umas sejam contrárias às outras em alguns aspectos (Rachels, 2006).

Notadamente, vários autores tratam ética e moral como sinônimos e até utilizam um ou outro conceito sem fazer distinção. Vários dicionários da língua portuguesa, inclusive, reforçam essa sinonímia, que do ponto de vista acadêmico é aceitável. Não obstante, existem formas convencionais de se diferenciar ética e moral, porém, essa diferenciação se resume ao nível da abstração (Taille, 2010).

Nesse sentido, Aristóteles (2003) afirma que o 
termo ética deriva do termo ethos, que significa hábito, costume, pois a virtude ética não é da natureza do homem, mas este a adquire pelos costumes. Diferentemente dos demais seres viventes, que são condenados a agir sempre dentro do que ordena sua natureza, o homem tem a liberdade de escolha.

Se por um lado a virtude ética não é da natureza humana, não é tampouco, contrária. Independente do meio que nasce, o homem é apto à virtude ética, devendo aperfeiçoá-la durante a sua vida. Sua própria razão em combate com seus instintos resulta no que ele é capaz de oferecer ao convívio social (Aristóteles, 2003).

A ética se sobrepõe ao estado de natureza. Ela faz com que o indivíduo tome suas decisões objetivando uma convivência coletiva harmoniosa, libertando-se, portanto, de seu egoísmo (Marcuse, 1982).

A definição de moral proposta por Kant (1993) afirma que toda moral tem inspiração em um imperativo categórico, derivando, dessa forma, de um sentimento de dever incondicional. De acordo com essa definição, o julgamento moral fornecerá ao homem, de maneira determinada, uma indicação de como deve agir, mas não lhe tolherá o direito de tomar a decisão por si mesmo.

Mesmo sendo a liberdade um dos pressupostos da ética, tomá-la como valor supremo pode-se levar à promoção de atitudes antiéticas. Conforme ensinado por Bastiani (2008), o primeiro impulso estaria pautado no pensamento de que se o indivíduo é livre, tem a prerrogativa de subjugar o outro. Desse modo, o excesso de liberdade poderia gerar a perda da humanidade.

Taille (2010) afirma que a moral pressupõe um sentimento de obrigatoriedade. Intimamente, o sujeito se acha obrigado a agir de um modo determinado, qualquer que seja o conteúdo que está sendo objeto do julgamento. E esse sentimento estará comprometido com valores, princípios e regras que anteriormente o indivíduo já possuía.

Por outro lado, a ética pode ser tomada como uma exigência moral auto imposta pelo indivíduo, diferenciando-se, contudo, da teoria kantiana, no que se refere à origem dos imperativos. Nesse ponto de vista, são três as fontes do imperativo categórico: a fonte externa, que seriam as crenças e normas sociais, pré-estabelecidas; a fonte interna, representada pela consciência do indivíduo; e uma fonte que seria anterior à própria organização dos seres vivos (Morin, 2005).

$\mathrm{Na}$ visão de Lipovetsky (2005), atualmente a sociedade está vivenciando o “crepúsculo do dever”, em razão do qual, o homem deixa de enxergar importância em qualquer outra coisa que não seja ele mesmo. 0 ser humano vive diariamente um conflito de possibilidades, sendo obrigado a fazer suas escolhas a todo instante.

\section{Administração Pública brasileira: breve histórico}

Com a evolução natural da sociedade, o Brasil desenvolveu variações nos modelos de Administração Pública de acordo com o contexto histórico. Esses modelos representaram uma adaptação do país a cada ciclo político vivenciado. Drumond, Silveira e Silva (2014) classificam esses modelos como patrimonialista, que vai de 1500 a 1930; burocrático, que vai de 1930 a 1990; gerencialista, a partir da década de 1990; e societal, a partir de 2000.
O modelo patrimonialista foi introduzido no Brasil como herança portuguesa. Embora tenha como característica a dominação, o patrimonialismo é marcado pela ausência de conflito estrutural, no qual não se verifica o desejo interno de mudança (BresserPereira, 1996).

Contudo, após a ascensão do capitalismo industrial, se fez necessário um modelo de Administração que fosse capaz de distinguir claramente o público e o privado. Surge assim, o modelo burocrático, que foi capaz de atender momentaneamente, às necessidades do país. Sua finalidade era garantir a máxima eficiência possível, tendo como principal característica a racionalidade. Seu sucesso aparente se deu mais em razão da inoperância do antigo modelo do que de sua compatibilidade com os anseios da sociedade. Pois, na verdade o modelo não era rápido, nem eficiente, e nem barato (Faoro, 1958).

Entretanto, o Brasil não foi capaz de formar um modelo de Administração Pública burocrática consolidado, não alcançando, portanto, a eficiência cobiçada (Matias-Pereira, 2008). Assim, a partir da década de 70 passa a ganhar forças, um movimento voltado para uma nova reforma administrativa, que seria o modelo gerencial (Bresser-Pereira, 1996).

Apesar das tentativas anteriores de se instituir uma nova reforma administrativa, nos anos 30, bem como posteriormente, com o surgimento do Decreto-Lei $\mathrm{n}^{\circ}$ 200/67, Drumond et al (2014) afirmam que o modelo gerencial somente ganhou forças após a crise do modelo burocrático, que teve seu ápice com a promulgação da Constituição de 1988, mormente a administração de empresas começa a influenciar fortemente a Administração Pública.

Contudo, embora essa proposta de reforma tenha sido construída sobre os princípios políticos da participação popular, accountability e controle social, a forma como foi idealizada e conduzida apresentou muitas falhas, especialmente pela insuficiência de mecanismos de coordenação política (Matias-Pereira, 2008).

Surge em seguida, o modelo societal, a partir dos movimentos da sociedade civil, que questionavam o protagonismo do Estado na condução da gestão pública. Esse modelo, que se encontra ainda em construção, busca um projeto político alternativo ao gerencialismo, que apresente um novo modelo de desenvolvimento, em oposição à crise do nacional desenvolvimentismo e que, ao mesmo tempo, seja capaz de reorganizar o aparelho do Estado (Drumond et al, 2014).

\section{Parâmetros constitucionais da ética na Administração Pública}

O Estado Democrático de Direito foi consolidado no Brasil, a partir da introdução de novos mecanismos no texto constitucional, como a garantia jurisdicional de supremacia da constituição, a efetividade dos direitos fundamentais e ampliação do conceito de democracia, e ainda o princípio da soberania popular, que ficou caracterizado como uma das colunas que sustentam esse novo modelo (Novelino, 2014).

De forma expressa, o Art. $1^{\circ}$ da Constituição 
Federal de 1988 afirma que a República Federativa do Brasil se constitui em Estado Democrático de Direito, listando em seguida, seus fundamentos: a soberania, a cidadania, a dignidade da pessoa humana, os valores sociais do trabalho e o pluralismo político (Brasil, 1988).

Dentre os fundamentos citados, a cidadania pode ser considerada palavra-chave no discurso democrático, se for considerado o seu conceito ligado ao reconhecimento e respeito entre os indivíduos. Assim, cidadania pode ser entendida como a participação efetiva dos indivíduos de uma dada coletividade, visando à busca pela igualdade nos mais variados aspectos das relações humanas, utilizando como ferramenta, o avanço dos direitos civis, políticos e sociais (Rolnik, 1992).

Baseando-se na teoria de que o conceito de cidadania está fortemente ligado à titularidade de direitos e preocupação com a coisa pública (Mendes \& Andrade, 2010), a ética na Administração Pública pode ser considerada eficaz na proteção dos direitos fundamentais e na busca pelo bem comum, garantindo-se assim, a chamada dimensão material da "democracia substancial" (Streck, 1999).

Na concepção de Hegel (1988), as instituições sociais e as leis que regem a sociedade são formadas por um conjunto de vontades particulares e, ao mesmo tempo, dos grupos sociais, que juntas representam a realização da liberdade em seu grau mais elevado. 0 indivíduo se reconhece cidadão quando desenvolve a consciência de sua liberdade e se reconhece como membro de uma coletividade.

Outro conceito que está fortemente ligado à conduta ética na Administração Pública é a dignidade da pessoa humana, presente em quase todos os textos constitucionais do segundo pós-guerra e consagrado em importantes declarações universais de direitos humanos. 0 conceito de dignidade da pessoa humana é aceito como uma espécie de consenso teórico universal. 0 fato de estar formalmente presente nas constituições converte-a de simples valor moral e filosófico a conteúdo tipicamente jurídico e autônomo (Novelino, 2014).

\section{Teoria institucional}

Apesar da complexidade do tema, a teoria institucional pode ser definida de forma simples, podendo ser entendida, grosso modo, como um conjunto de regras que orientam a interação entre os indivíduos de uma sociedade (Gala, 2003).

Dessa forma, as instituições podem ser consideradas como simples regras, mas que, ao mesmo tempo, constituem fundamentos para o comportamento político. A partir dessa definição cabe a subdivisão do conceito de instituições em formais e informais. As instituições formais são aquelas advindas da legislação escrita, as informais, por sua vez, podem ser definidas como sendo os padrões culturais de uma sociedade (Procopiuck, 2013).

Partindo-se da subdivisão supratranscrita, pode-se considerar que essas regras, internas e externas, exercem verdadeiras influências nas organizações, conduzindo-as sob a legitimidade de procedimentos operacionais padrão, o que faz com que essa teoria revele uma faceta, ao mesmo tempo, rica e complexa das organizações (Zucker, 1987 como citado em Nascimento, Rodrigues \& Megliorini, 2010). Em outras palavras, estudar as instituições é estudar a sociedade em ação. Mesmo que seja uma ação desenvolvida dentro de limites sociais solidamente estabelecidos (Peci, 2006).

No dizer de Berger e Luckmenn (1964), o processo de institucionalização pode ser entendido como uma abordagem simbólico-interpretativa da construção social de uma organização, em razão da influência exercida sobre a mudança organizacional e às suas características.

O conceito de instituição tem sido utilizado há vários anos por diversos campos da ciência. Mesmo sendo alvo de muitas controvérsias em sua concepção teórica, bem como na sua aplicação prática, vários estudos sociológicos, organizacionais e antropológicos vêm desenvolvendo estudos voltados à teoria das instituições, quase sempre convergindo seu entendimento de que o institucionalismo é uma forma de estabelecimento, buscando uma estabilidade relativa de algum tipo de forma social (Hughes, 1936 como citado em Peci, 2006).

Desta forma, um dos objetivos principais do institucionalismo, mais precisamente em sua forma clássica, seria identificar o grau de influência que as instituições formais exercem nos processos sociais, bem como nas estratégias políticas de uma sociedade (Procopiuck, 2013). Assim, o institucionalismo pode ser compreendido como sendo um fenômeno social, através do qual, se torna possível uma identificação dos aspectos sociais do comportamento coletivo permanente. Em outras palavras, utiliza-se como ponto de referência a coletividade, a fim de se compreender o indivíduo (Peci, 2006).

Em razão da atual dinâmica contextual na qual está inserida a Administração Pública, algumas características do institucionalismo clássico, como o legalismo exacerbado, além do formalismo excessivo, o tornou obsoleto. Desta forma, as ciências sociais, na atualidade, utilizam o chamado neoinstitucionalismo, que surgiu como resposta às limitações da antiga teoria, utilizando como abordagem principal a teoria organizacional e a teoria da decisão (Procopiuck, 2013).

Embora as instituições atuem proporcionando a estabilização política, por outro lado revela um dinamismo considerável, quando sua construção é baseada na busca por mudanças nas regras e rotinas. Assim, segundo o mesmo autor, o institucionalismo simplifica a vida política, considerando que dele são extraídas regras que definem qual a conduta a ser seguida por um administrador, um representante eleito, ou até mesmo pelo homem médio.

Assim, na visão de Scott (2007, como citado em Pereira, 2012), considera-se que as estruturas e rotinas organizacionais decorrem, justamente, de regras contextualmente institucionalizadas, remetendo às questões voltadas à legitimidade e à concepção de ambiente. Nessa mesma linha, há um isomorfismo no neoinstitucionalismo, que se traduz num movimento coletivo através do qual, as técnicas utilizadas pela 
organização decorrem de sua aprovação por parte da sociedade (Melo \& Helal, 2014).

A interação social e a interpretação da realidade, feita pelo indivíduo é o que traduz uma instituição. Os indivíduos governam seus atos e comportamentos, nas interações sociais, pelos hábitos. Contudo, esse comportamento é regulado pelo contexto social de interação ao qual está exposto (Berger \& Luckmann, 1964).

Além do indivíduo e a partir dele, existem outros fatores que podem influenciar diretamente no desenvolvimento de uma organização, agindo como molas propulsoras para a inovação, como, por exemplo, a inovação tecnológica, as forças de mercado, as denominadas forças causais, bem como as normas legais positivadas (Nascimento et al, 2010).

Para os autores, a importância do estudo da teoria institucional no campo da Administração Pública decorre do fato de que essas teorias foram incorporadas aos sistemas de gestão estratégica e de desempenho, das organizações modernas, considerando as normas sociais por elas adotadas.

Por fim, cabe ressaltar que, de acordo com um dos grandes estudiosos da teoria institucional, Douglass North, os principais agentes da sociedade são as organizações. A fim de explicar o papel destas, o autor se utiliza da metáfora dos jogos esportivos, a qual afirma que "Se as instituições são as regras do jogo, as organizações representam os diversos times que disputam o campeonato da sociedade" (Gala, 2003, p. 101).

\section{Considerações sobre a percepção}

Ao se falar em percepção, não há como se furtar de entendê-la como uma atividade sensorial do ser humano, ou seja, cada ser absorveria as informações do meio através de seus órgãos responsáveis pelos sentidos. Assim, o senso comum, ao tratar sobre o tema, poderia concebê-lo como sendo o ato pelo qual o ser tem consciência de um fato ou objeto, utilizando como instrumentos para tal, os órgãos dos sentidos.

Perceber significa trazer algo à consciência, formar representações mentais, utilizando os sentidos para isso. É um ato de cognição intuitiva imediata que avalia alguma ideia ou situação. A matéria da percepção seria, portanto, a sensação. Pela teoria empirista, toda a fonte de conhecimento humano advém da percepção. Por outro lado, pela teoria racionalista, a percepção não seria totalmente confiável por depender de elementos sensíveis, embora, considere, em última análise, que a causa do que é percebido é justamente o que é captado pelos sentidos (Japiassú \& Marcondes, 2008).

A primeira impressão, ou sensação, é, portanto, a forma como o indivíduo que a sente é afetado, é a experiência de um estado de si mesmo. Para que se concretize o fenômeno perceptivo, porém, se faz necessária uma visão mais ampla sobre o objeto a fim de identificar suas qualidades. Essa análise mais aprofundada revelará em cada qualidade as significações que a habitam (Merleau-Ponty, 1999).

Nesse contexto, pode-se considerar a percepção como um correlato da realidade, muito mais do que uma cópia do que é registrado pelos sentidos. É uma interpretação da realidade objetiva, a partir da atribuição de significado às informações recebidas. (Merleau-Ponty, 1999).

Inicialmente, os estudos sobre percepção eram voltados para os mecanismos físicos e biológicos do fenômeno, porém, esse enfoque passa a ser superado, conforme ensina Merleau-Ponty (1999), com o surgimento da teoria Gestalt, que vem afirmar que somente através da percepção do todo é que a razão é capaz de absorver um conceito ou imagem. Em outras palavras, não se adquire o conhecimento do todo através de suas partes, mas, ao contrário, se adquire o conhecimento das partes através do todo.

Dessa forma, a percepção não se trata de um simples processamento de informações. A percepção é também um processo criador. 0 antigo sistema linear dá lugar a um sistema circular, que pode ser denominado de organismo-entorno. Esse sistema complexo submete as informações recebidas pelos sentidos, de forma sinestésica, aos valores previamente adquiridos através das experiências. Experiências estas que formam um ser permanentemente inacabado e que se reorganiza a cada novo estímulo recebido pelos sentidos (Nóbrega, 2008).

Importante ressaltar que essa constante reorganização da mente não reflete uma volubilidade do ser. Trata-se na verdade do que ficou conhecido como autopoiesis. Fenômeno através do qual, o ser possui certa medida de estabilidade, mas que não o torna imutável frente às experiências que o meio the proporciona. Da mesma forma que a ética pressupõe a liberdade de escolha racional do indivíduo, a autopoiesis considera o ser biológico como uma unidade autônoma capaz de se autocriar, se reorganizar. A interação com o meio desencadeia a reflexão que irá reorganizar o indivíduo, do ponto de vista cognitivo (Maturana \& Varela, 1995).

\section{Elementos metodológicos da pesquisa}

0 método de pesquisa utilizado no presente trabalho foi o indutivo, considerando-se que parte de observações particulares, buscando-se atingir uma generalização da realidade observada (Bittar, 2016). Esse processo é caracterizado, principalmente, pelo fato de que, apoiando-se nos dados observados, se torna possível a obtenção de conclusões gerais (Lakatos \& Marconi, 2017).

0 presente trabalho se refere à realização de uma pesquisa de campo do tipo exploratório-descritiva, que pretendia descrever a realidade observada objetivando a elevação do nível de compreensão acerca do campo de estudo, bem como a posterior elaboração de conceitos gerais (Lakatos \& Marconi, 2017).

Trata-se de uma pesquisa qualitativa, tendo em vista que o estudo em tela busca a aquisição de uma visão holística acerca do tema, e não a mera coleta e análise de informações estatísticas. Conforme apontado por Creswell (2010), o trabalho é fundamentalmente interpretativo e cabe ao pesquisador a descrição, análise e posterior interpretação dos dados coletados.

Partiu-se de uma pesquisa bibliográfica que buscou uma integração entre os temas envolvidos, com o intuito de fornecer um arcabouço teórico básico à pesquisa e que, posteriormente, foi utilizada como base comparativa, contrastando com as conclusões obtidas 
na análise dos dados, conclusões estas embasadas na realidade empírica observada pelo pesquisador (Creswell, 2010).

Para a parte empírica da pesquisa, classificou-se como população investigada, todos os que compõem a comunidade universitária do CCBS, quais sejam os discentes dos três cursos de graduação ligados ao Centro, servidores docentes e técnico-administrativos, conforme definido no Estatuto da Instituição.

A amostra representativa foi determinada a partir da proposta de Bruni (2007), considerada adequada, por se tratar de uma população finita e variável qualitativa. Para tanto, foi considerado o nível de confiança em $95 \%$ e a margem de erro de $4 \%$. Para tanto, a coleta de dados foi realizada sobre uma amostragem aleatória simples, em 335 pessoas integrantes da população, dos quais 262 são discentes, 53 são servidores docentes e 20 são servidores técnico-administrativos (Martins \& Theóphilo, 2016).

Para a coleta dos dados foi utilizado um questionário com 27 itens, com respostas objetivas dispostas na forma de uma escala de resposta psicométrica do tipo Likert, com cinco categorias diferentes de respostas (Likert de cinco pontos), que vai de "sempre" até "nunca". Portanto, é uma escala unidimensional, com âncoras extremas, um ponto neutro no meio "tenho dúvida", e âncoras intermediárias "quase sempre" e "quase nunca" (Vieira \& Dalmoro, 2008), instrumento científico considerado adequado para mensuração e observação de fenômenos sociais (Lakatos \& Marconi, 2017).

Levando em consideração que por ocasião da aplicação dos questionários, a realização da pesquisa de campo envolveria a participação de seres humanos, o presente trabalho foi submetido e, posteriormente, aprovado pelo Comitê de Ética em Pesquisa em Seres Humanos do Hospital Universitário Alcides Carneiro, em Campina Grande - PB, a fim de que fossem cumpridas todas as exigências legais e éticas.

\section{Apresentação e discussão dos resultados}

No que se refere às questões gerais sobre a ética, a maioria das pessoas pesquisadas responderam que se consideram capazes de discernir se uma situação prática do cotidiano está ou não de acordo com a ética. Somente $1,19 \%$ das pessoas disseram que quase nunca são capazes de identificar uma atitude ética no seu dia-a-dia. Enquanto $85,07 \%$ das pessoas responderam que são capazes de identificá-las ao se deparar com alguma situação real.

Desses dados, pode-se inferir que ao responder às demais questões do instrumento de pesquisa, o participante o fez com a convicção de que sua percepção muito poderia contribuir para os resultados deste trabalho, pois, apesar de se tratar de um tema consideravelmente controverso como a ética, o respondente se considerou capaz de julgar, a partir da sua observância, a conduta ética dos servidores da Instituição.

Contudo, a ética, sobretudo no serviço público, corresponde a um tema de difícil assimilação. Embora os participantes da pesquisa tenham se considerado aptos a distinguir a ética em alguma situação fática, não significa que o são. Até porque essa pesquisa não os submeteu a nenhum tipo de teste nesse sentido. Ademais, o fato de ter que exercer um julgamento ético acerca da conduta de outrem, pode causar apreensão e insegurança no indivíduo (Mendes, 2014; Mendes \& Andrade, 2010).

Ao serem questionadas sobre a possibilidade se adquirir a ética através dos costumes, bem como da possibilidade da ética ser repassada como um ensinamento, mais de $87,5 \%$ das pessoas foram favoráveis à ideia. Pensamento que corrobora com as teorias apresentadas por Aristóteles (2003), quando afirma que a ética não é inata ao homem, nem tampouco the é contrária, mas construída de acordo com os costumes e os estímulos oferecidos pelo meio.

Com relação à necessidade de se transformar normas éticas em leis escritas, para que assim sejam respeitadas, $38 \%$ das pessoas disse ter dúvida, o que é compreensível, levando-se em consideração a complexidade do tema. Por outro lado, dentre os que ofereceram resposta à questão, $76,44 \%$ acreditam que as normas éticas somente seriam efetivas se se tornassem leis escritas.

Essa é uma questão bastante delicada, haja vista a concordância de vários autores de que a ética está fortemente ligada ao costume. Na visão de Kant (1993), a moral está atrelada a uma espécie de imperativo categórico, que no pensamento de Taille (2010) é um julgamento baseado nos valores, princípios e regras que o indivíduo já possuía, que o impelem a agir de determinada maneira, o que é racionalizado no sentimento de obrigação. Em suma, a pessoa cumpre a regra porque acredita que é a atitude correta, independente da existência de lei escrita que o obrigue.

Nesse sentido, é um erro relacionar a ética com a obediência às leis, de forma absoluta. Deve ser levado em consideração que nem mesmo há a garantia de que as leis em vigor no país estão pautadas na ética. Mesmo que o fosse, é preciso considerar que a sociedade evolui e com ela seus costumes, por conseguinte, o conceito socialmente aceito acerca da ética (Mendes e Andrade, 2010). Outrossim, o resultado revela um descrédito, por parte da população investigada, de que a sociedade poderia agir corretamente unicamente por respeito à coletividade ou mesmo impulsionado pela virtude ética (Aristóteles, 1991).

Outra questão que merece destaque é com relação à frequência que surgem situações de extrema necessidade, que justifiquem, mesmo que momentaneamente, a não observância de alguma norma ética. Dentre as questões constantes no instrumento de pesquisa aplicado, esta foi a que apresentou maior distribuição de respostas, conforme a Tabela abaixo.

Tabela 1 - Situações que justificam a não observância das normas éticas.

\begin{tabular}{ccc}
\hline $\begin{array}{c}\text { Item } \\
\text { respondido }\end{array}$ & $\begin{array}{c}\text { Quantidade } \\
\text { de respostas }\end{array}$ & Percentual \\
\hline Sempre & 6 & $1,79 \%$ \\
Quase sempre & 77 & $22,99 \%$ \\
Tenho dúvida & 110 & $32,83 \%$ \\
Quase nunca & 128 & $38,21 \%$
\end{tabular}




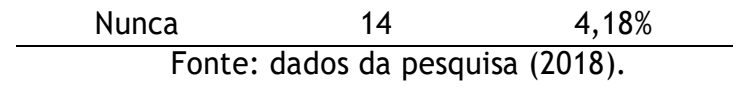

Tudo o que é ético, da forma como se conhece hoje não o foi desde sempre. 0 conceito de ética sofre variações no decorrer do tempo e o agir, que hoje se conhece como atitude ética, na verdade é um acordo social histórico, que em algum momento foi a transgressão de alguma norma ética. 0 certo e o errado dependem de um julgamento de valor específico, que por sua vez dependerá de fatores externos. Sendo assim, para não condenar a sociedade a uma estagnação impedindo sua evolução, deve-se reconhecer, com a devida moderação, que certos valores, socialmente estabelecidos, podem ser relativizados.

Vale aqui ressaltar que o que pode ser relativizado são os valores culturais e morais pré-estabelecidos, haja vista a evolução natural da sociedade, que transforma o pensamento do homem e o adapta às condições do meio em que vive. A ética jamais deve ser relativizada. Ela deve sim, ser transformada e renovada a fim de que possa acompanhar aquela evolução social.

A pesquisa revelou também, que o grau de conhecimento acerca do Código de Ética e da Comissão de Ética a UFCG, bem como do trabalho por ela realizado, dentro da população pesquisada, é extremamente baixo. Somente $9,84 \%$ das pessoas afirmaram conhecer o referido Código. No que se refere à existência da Comissão de Ética da UFCG, 25,66\% declaram possuir algum conhecimento. E ainda, quando questionados sobre a instauração de processos para apuração de faltas éticas, no âmbito da UFCG, somente 6,9\% afirmaram ter conhecimento. Esses dados revelam que não só a Comissão de Ética da UFCG é pouco conhecida como pouquíssimas pessoas têm conhecimento acerca do seu trabalho.

A função educacional do Código de Ética é uma das ações prioritárias na promoção e formação da ética no serviço público federal. 0 baixo conhecimento a respeito das normas pode representar um dos principais obstáculos para uma adequada promoção da ética, pois, a efetividade de um código de conduta depende diretamente do quanto ele é conhecido (Mendes, 2014).

Da amostra tomada para a presente pesquisa, grande parte é composta por discentes dos cursos de graduação, de quem não se espera um vasto conhecimento sobre 0 Decreto $1.171 / 94$, visto que diz respeito à conduta dos agentes públicos. No entanto, um aspecto a ser destacado é que, mesmo dentre os servidores públicos, a quem compete conhecer e cumprir o Código de Ética Profissional, o nível de conhecimento permaneceu baixo. Ao serem questionados sobre a existência do Código de Ética e da Comissão de Ética da Instituição, os resultados obtidos têm a mesma tendência. Dos 73 servidores que responderam ao questionário, somente 17 demonstraram ter conhecimento, ou seja, $76,71 \%$ dos servidores desconhecem ambos.

Importante ressaltar ainda que, dos 56 servidores que ignoram a existência do Código de Ética, 10,71\% ocupam cargos de gestão. Não que as questões éticas interessem mais a uns do que a outros. A todos cabe a fiscalização sobre a gerência da coisa pública e o agir de acordo com a ética é um dever de todos. Porém, daqueles se espera uma observância um pouco mais apurada, haja vista a assunção de uma parcela de responsabilidade maior com a coisa pública.
A pesquisa indagou ainda aos participantes, se na sua percepção, o servidor, quando se encontra diante de duas opções, escolhe a mais vantajosa para o bem comum. Os resultados obtidos representaram um aspecto positivo nos resultados dessa pesquisa. Para essa questão, $82,2 \%$ responderam que o servidor, diante de duas opções, escolhe a mais vantajosa para o bem comum. 0 que retrata uma percepção positiva da comunidade pesquisada no que se refere ao serviço público prestado pelo Centro, pois guarda estreita relação com o conceito de ética proposto na literatura estudada.

Nesse sentido, pode se considerar que o ser humano é impelido a fazer escolhas a todo instante, cabendo a cada indivíduo tomar as decisões mais convenientes, de acordo com seu próprio juízo de valor, tendo consciência de que essas escolhas repercutem em si mesmo, no outro e na coletividade (Gomes, 2014).

Nessa mesma linha, na definição de Marcuse (1982), para se falar em ética é necessário sobrepujar o estado de natureza, a fim de que o indivíduo possa libertar-se do pensamento egoístico, passando a considerar os outros seres, tomando suas decisões, objetivando uma convivência coletiva harmoniosa. Dessa forma, o sujeito poderia abrir mão do seu próprio bem-estar, em benefício do bem-estar coletivo.

Outro aspecto abordado no instrumento de pesquisa, que se destacou tanto pela relevância e atualidade do tema quanto pelo resultado obtido, colocou em discussão o tratamento que o servidor dispensa aos usuários dos serviços públicos. Os participantes da pesquisa puderam apontar se há cortesia e urbanidade no atendimento, bem como se este é desempenhado sem qualquer preconceito ou distinção de raça, nacionalidade, orientação sexual, cor, idade, crença, convicção política e posição social, o que, além de uma obrigação enquanto cidadão é reconhecido como um dever legal, previsto no Decreto $\mathrm{n}^{\circ} 1.171 / 94$.

A Administração Pública tem também uma função de inserção social, essencialmente em ambientes nos quais se promovam a formação intelectual e cidadã. Nesse sentido, na presente pesquisa pôde-se verificar um alto grau de satisfação dos pesquisados nesse sentido, uma vez que $95,5 \%$ das pessoas afirmaram que é percebido um tratamento urbano, cortês e livre de qualquer discriminação, enquanto $4,5 \%$ das pessoas afirmaram o contrário.

É certo que a diversidade de crença, raça, orientação sexual, dentre outros tipos, sempre fizeram parte da realidade brasileira. E a sociedade atual, que é marcada pela falta de tolerância com as diferenças, parece estar trilhando o caminho inverso da evolução social, em direção ao estado de natureza. Assim, é de grande valia a investigação da conduta do servidor público nesse sentido, a fim de que possa ser constatado se está sendo conferido o respeito devido à sociedade em geral, visto que o oferecimento de um tratamento desrespeitoso, sobretudo às pessoas que direta ou indiretamente pagam seus tributos significa causar-lhes dano moral (Brasil, 1994).

Outrossim, a busca por uma sociedade mais justa, com a redução das desigualdades sociais e regionais e 0 
respeito à dignidade da pessoa humana constituem, respectivamente, objetivos da República Federativa do Brasil e Fundamentos do Estado Democrático de Direito, estabelecidos pela Carta Magna de 1988 (Brasil, 1988).

0 grupo de questões que tratava das condutas vedadas aos servidores foi o que apresentou o maior índice de pessoas que apresentaram respostas neutras. Os 7 itens que compuseram o bloco apresentaram uma média de $43,37 \%$ de dúvida, donde pode-se deduzir que o pesquisado preferiu não opinar sobre o tema, pois, embora nunca tenha tomado conhecimento da prática de alguma das faltas éticas elencadas no questionário, por algum motivo não exclui a possibilidade de que aconteça. Outra razão aparente seria a existência de algum receio por parte do pesquisado, de apontar possíveis faltas éticas praticadas pelo servidor.

Indícios dessa teoria podem ser verificados ao se correlacionar dois itens do instrumento de pesquisa, que abordavam situações muito parecidas, porém, apresentadas em sentido oposto. 0 primeiro questionou se o servidor exerce suas atribuições em tempo hábil, evitando a procrastinação. 0 segundo item indagou ao participante se - servidor utiliza artifícios visando à procrastinação de forma intencional.

Ao serem questionados sobre a utilização de artifícios, por parte do servidor, visando à procrastinação, 35 pessoas sinalizaram que existe esta prática. No entanto, ao serem questionados se o servidor exerce as suas atribuições evitando a procrastinação, 59 pessoas disseram que não. Ocorre que, ao confrontar as respostas aos itens citados, conforme Tabela abaixo, há uma discrepância de quase $70 \%$ nos resultados, o que pode significar que o participante da pesquisa é mais comedido ao apontar que o servidor pratica alguma ação que é proibida por lei e se sente mais à vontade em afirmar que ele deixa de fazer conforme ela orienta.

Tabela 2 - Comparativo das respostas acerca da procrastinação.

\begin{tabular}{ccc}
\hline Abordagem & Sim & Não \\
\hline $\begin{array}{c}\text { O servidor utilizar artifícios } \\
\text { para procrastinar? }\end{array}$ & $17,59 \%$ & $82,42 \%$ \\
$\begin{array}{c}\text { O servidor evita a } \\
\text { procrastinação? }\end{array}$ & $70,65 \%$ & $29,35 \%$ \\
\hline Fonte: dados da pesquisa (2018). &
\end{tabular}

Mesmo que a tendência da resposta tenha sido a mesma, pois em ambos os casos, a maioria das pessoas afirmou que o servidor não procrastina, o que está sendo ressaltado aqui é que, dependendo da forma com que o tema é abordado, mesmo que em pequena escala, o resultado pode sofrer variações.

Tratar sobre a ética, por si só, trás consigo uma parcela de receio. Muitas pessoas consideram a ética e os próprios códigos de ética, das mais diversas profissões, como ameaças. Segundo Mendes e Andrade (2010), não só existe o receio de se trabalhar numa comissão de ética, por haver a possibilidade de ferir certos interesses de superiores hierárquicos, quanto de se fazer denúncia sobre infrações éticas praticadas no órgão, mesmo que não haja relação de subordinação.

Nesse mesmo sentido, a complexidade do processo de prevenção das faltas éticas pode ser traduzido na existência de certo receio em denunciar as transgressões às normas éticas, bem como em apurar essas denúncias (Organização para Cooperação e Desenvolvimento Econômico, 1998).

Por fim, os participantes foram submetidos a um grupo de questões que tinham como objetivo, examinar as possíveis consequências decorrentes da percepção da comunidade universitária, que de algum modo, podem interferir na rotina acadêmica e administrativa do órgçao. Os resultados obtidos estão dispostos na Tabela abaixo.

Tabela 3 - Consequências da percepção da ética.

\begin{tabular}{|c|c|c|}
\hline Abordagem & Sim & Não \\
\hline $\begin{array}{c}\text { A comunidade universitária } \\
\text { do CCBS age de acordo com } \\
\text { as normas éticas? }\end{array}$ & $92,9 \%$ & $7,1 \%$ \\
\hline $\begin{array}{c}\text { Ao observar o } \\
\text { comportamento da } \\
\text { comunidade universitária, há } \\
\text { o sentimento de incentivo ao } \\
\text { cumprimento das normas } \\
\text { éticas? }\end{array}$ & $87 \%$ & $13 \%$ \\
\hline $\begin{array}{l}\text { Vale a pena agir de acordo } \\
\text { com as normas éticas, } \\
\text { mesmo que a maioria das } \\
\text { pessoas não o faça? }\end{array}$ & $100 \%$ & $0 \%$ \\
\hline
\end{tabular}

De acordo com os resultados obtidos, foi possível identificar que a concepção adstrita à comunidade universitária do CCBS acerca do cumprimento das normas éticas dentro do Centro é, de forma mais generalista, positiva, haja vista a maioria das pessoas terem sinalizado que as normas éticas são cumpridas. Assim, partindo desse ponto de vista, os resultados encontrados nesse último grupo de questões estavam dentro do esperado, no que se refere às consequências práticas da percepção da ética identificada.

Os resultados obtidos revelam que, não obstante a estrutura hierarquizada, somada aos vícios patrimonialistas incrustados na Administração Pública em geral, os quais podem dificultar a implantação de padrões éticos, esta proposição não pode ser generalizada (Mendes e Andrade, 2010), pois, não obstante essa pesquisa tenha identificado um raso nível de conhecimento, tanto sobre o Código de Ética referente ao Decreto $n^{\circ} 1.171 / 94$ quanto da Comissão de Ética da UFCG, os resultados apontam para a existência de uma consciência ética da população estudada, traduzida na sua colaboração espontânea. Proposição que pode ser depreendida do conceito de que ética pressupõe liberdade de agir e capacidade de discernimento entre o certo e o errado (Gomes, 2014).

A conduta ética do agente público fortalece as instituições, estruturas e processos que influenciam de forma direta, no desenvolvimento do país, pois pode ser 
considerada como um instrumento primário para o alcance dos objetivos políticos, econômicos e sociais da nação (Mendes, 2014).

Se, consoante à teoria aristotélica, confirmada pelos resultados obtidos no presente estudo, a ética, tanto pode ser ensinada quanto pode ser adquirida pelo costume, o exemplo dado pelo servidor público é primordial na persecução de uma conduta ética generalizada dentro do próprio órgão, e tida como ideal a ser alcançado em toda a sociedade. Esse exemplo de conduta traduz, em parte, a influência exercida pelas instituições, nos processos sociais e nas estratégias políticas da sociedade, demonstrando de forma bastante clara que, de fato, o institucionalismo pode ser compreendido como um fenômeno social (Aristóteles, 2003; Peci, 2006; Procopiuck, 2013).

De modo geral, os resultados encontrados indicam a existência, na comunidade universitária do CCBS, mesmo que no campo da teoria, de uma consciência sobre o valor da conduta ética e a vontade de que ela seja cumprida. De acordo com a teoria kantiana essa vontade é característica da razão humana que, podendo agir de forma diversa, escolhe, pela constrição, derivar suas ações das leis, pois a vontade, nada mais é que a razão prática. Noutras palavras, as ações são regidas pelo imperativo categórico (Kant, 1993).

\section{Proposição}

Através dos resultados obtidos com a pesquisa, vários aspectos deficitários puderam ser identificados na promoção da norma, e no seu cumprimento. A essência do Código de Ética se revela com um caráter mais pedagógico e menos estatístico, indo além da correção do ato já praticado. Assim, o trabalho em tela propôs algumas ações com vistas à promoção da ética (Mendes, 2014).

Dessa forma, propõe-se a criação de cursos de capacitação voltados para a comunidade universitária, que abordem a questão da ética no serviço público. Como forma de operacionalizar a realização desses cursos, deve-se considerar que muitos servidores da Instituição possuem habilidades específicas, que poderiam ser identificadas e, posteriormente, utilizadas na própria capacitação, reduzindo assim, os possíveis custos gerados nestas ações.

Outra proposta bastante eficaz na promoção do Código de Ética seria a utilização das mídias conhecidas como redes sociais. Recentemente, a UFCG lançou um perfil oficial na plataforma eletrônica denominada Instagram, uma rede social online que, segundo notícia publicada no sítio eletrônico da UFCG, atualmente conta com 50 milhões de usuários ativos em todo o mundo. Além da plataforma citada, a Universidade já possui perfil oficial ativo no Facebook e no Twitter.

Explorando esses meios de comunicação modernos, informações e campanhas de conscientização sobre as questões éticas poderiam ser divulgadas com muito mais facilidade e a uma velocidade inimaginável.

Outra opção viável seria a elaboração de uma cartilha educativa, baseada no Código de Ética, para ser distribuída em toda Universidade, com linguagem simples e direta, apresentando ilustrações em situações hipotéticas, até mesmo de maneira lúdica, com o objetivo de prestar esclarecimentos sobre situações complexas e delicadas, que fazem parte do dia-a-dia da Instituição.
0 método em questão pode representar uma forma muito pedagógica de se propagar as informações contidas no Código de Ética, alcançando e estimulando um número elevado de pessoas, a observar com mais cuidado os preceitos éticos, fixando os conhecimentos e sendo capazes de identificar eventuais desvios éticos de que tomem conhecimento.

Finalmente, propõe-se a criação de uma normatização interna de conduta ética própria da Instituição, a ser aplicada de forma subsidiária ao Código de Ética Federal. Cada órgão público tem suas particularidades, e num país de dimensões continentais, como é o Brasil, isso fica evidenciado em diversos aspectos, como a cultura, as condições climáticas e sociais, desenvolvimento econômico, entre outros.

Considerando o baixo nível de conhecimento acerca nas normas éticas, constatado no presente estudo, a Resolução sugerida, dentre outros temas, poderia determinar formas concretas de promoção da ética dentro do órgão, estabelecendo diretrizes nesse sentido, a serem seguidas, tanto pela Comissão de Ética, quanto pelos Centros de Ensino e os Órgãos Superiores da instituição.

\section{Considerações finais}

Analisar a ética no atual contexto político e social brasileiro se mostrou bastante desafiador. Os altos índices de corrupção e os casos frequentes de mau uso do patrimônio público, inevitavelmente, culminam na falta de confiança nas instituições públicas e na construção de uma imagem reprovável.

$\mathrm{Na}$ busca pela sensibilização geral no serviço público e pela formação de uma consciência baseada nos princípios e valores éticos, é de extrema importância a existência de instrumentos adequados para se promover discussões sobre o tema, não só no serviço público, mas em toda a sociedade.

Um agente público, antes de mais nada, pertence ao convívio social, meio no qual é formado o seu caráter. Para se alcançar alguma mudança política na Administração Pública, portanto, deve-se idealizar primeiramente, uma transformação no seio da sociedade, o que, analisado pelo viés aristotélico, pode ser determinante na conquista daqueles valores éticos.

O Código de Ética Profissional do Servidor Público Civil do Poder Executivo Federal, embora seja um instrumento limitado, pode ser considerado oportuno, mormente porque seu surgimento marcou um período de desconfiança e instabilidade política, decorrente de um processo de impeachment do então Presidente da República.

A atual conjuntura política do país, muito se assemelha à dessa época, visto que, em consequência de um novo processo de impeachment, uma crise dos valores morais tomou conta de boa parte das instituições públicas.

O objetivo da pesquisa, de analisar a percepção da comunidade universitária do CCBS, da UFCG, acerca da ética na Administração Pública foi atingido. Partindo de um ponto de vista mais generalizado, a amostra pesquisada considerou que, a comunidade universitária age em conformidade com as normas éticas que regem o 
serviço público federal.

Os participantes da pesquisa puderam expressar suas opiniões, objetivamente, sobre diversas situações práticas, de fácil observância na rotina diária do órgão objeto de estudo. Uma característica a ser destacada, com relação aos resultados da pesquisa, é a sensatez e seriedade demonstradas nas respostas dos participantes da pesquisa. Não obstante se tenha atingido um número elevado de respostas neutras, o que por si só, já reflete a cautela por parte do respondente, um número satisfatório de pessoas se posicionaram acerca das diversas questões, de maneira resoluta, muito embora tenham demonstrado certa resistência em dar respostas peremptórias "sempre" ou "nunca", havendo forte tendência, ao opinar sobre determinada questão, à escolha das respostas "quase sempre" ou "quase nunca".

Levando em consideração o pensamento de Taille (2010), como consequência da grande frequência de ocorrência das ações antiéticas, seria mais fácil ao respondente identificar, justamente, as transgressões éticas praticadas pelos que compõem o local objeto da pesquisa.

No entanto, de maneira geral, os resultados indicaram uma percepção relativamente positiva da comunidade universitária do CCBS acerca da prestação do serviço público no Centro, bem como a adequação da conduta dos servidores às normas éticas existentes.

Considerando as muitas críticas direcionadas diuturnamente pela sociedade em geral, ao serviço público, identificar a percepção dos próprios usuários deste serviço, reconhecendo o empenho e zelo com a coisa pública, mesmo que em pequena escala, sem dúvida alguma, pode ser considerado um avanço. É certo que esses dados estão longe de alcançar o nível ideal. No entanto, não se vive num mundo ideal. Pelo contrário, vive-se num mundo que atravessa uma profunda crise ética, sobretudo na Administração Pública. Portanto, cada esforço no sentido da ética deve ser reconhecido e incentivado.

Por outro lado, deve ser destacado o baixo índice de conhecimento acerca do Código de Ética Federal e da Comissão de Ética da Instituição. Em sua maioria, as pessoas pesquisadas afirmaram desconhecer as normas éticas referentes ao Decreto $\mathrm{n}^{\circ} 1.171 / 94$, bem como a existência da Comissão de Ética.

A falta de conhecimento acerca da norma existente representa um dos principais obstáculos na promoção da ética na Administração Pública. Os resultados obtidos revelam, portanto, a falência de uma das funções prioritárias do Código de Ética, a sua função pedagógica. Desta forma, restou demonstrada a necessidade de empenho efetivo por parte dos atores responsáveis pela disseminação da ética no serviço público federal.

Nesse sentido, da pesquisa surgiram algumas proposições que podem ser colocadas em prática a fim de auxiliar na promoção da ética, como por exemplo, a realização de cursos de capacitação que abordem o tema; a divulgação através das plataformas eletrônicas; a elaboração e distribuição de uma cartilha educativa; e a criação de uma normatização interna de conduta ética, como forma de subsidiar a aplicação do Código de Ética Profissional do Servidor Público Civil do Poder Executivo
Federal.

Com relação à coleta dos dados foram identificadas limitações no que se refere à obtenção da quantidade de participantes proposta. Para a aplicação dos questionários aos discentes, foi necessário o comparecimento em 17 das 32 turmas que compõem os 3 cursos de graduação do CCBS, a fim de se alcançar o número ideal de respondentes.

Como forma de instigação científica, visando à execução de estudos futuros, sugere-se a aplicação dessa pesquisa em outros Centros de Ensino da Universidade, como forma de expansão e aprofundamento nos resultados obtidos, bem como sua aplicação em outras instituições, o que poderia subsidiar os gestores na adoção de medidas, visando à promoção da ética na Administração Pública.

\section{Referências}

Aristóteles. (1991). Ética a Nicômaco (Tradução: L. Vallandro \& G. Bornheim, Trad.) (4a ed.) São Paulo: Nova Cultural.

Aristóteles. (2003). A ética: textos selecionados (C. M. Fonseca, Trad.) (2a ed.) Bauru: EDIPRO.

Bastiane, M. (2008). O sentido do humano como responsabilidade pelo outro no pensamento de Levinas. Dissertação de Mestrado. Faculdade de Filosofia e Ciências Humanas da Pontífica Universidade Católica do Rio Grande do Sul, Porto Alegre, RS, Brasil.

Berger, P. L., \& Luckmann, T. (1964). A construção social da realidade (29a ed.) Petrópolis: Vozes.

Bittar, E. C. B. (2016). Metodologia da pesquisa juriadica: teoria e prantica da monografia para os cursos de direito (14a ed.) São Paulo: Saraiva.

Bresser-Pereira, L. C. (1996). Da administração pública burocrática à gerencial. Revista do Serviço Público, 47(1), 2-28, janeiro/abril.

Bruni, A. L. (2007). Estatística aplicada à gestão empresarial São Paulo: Atlas, p. 388.

Constituição da República Federativa do Brasil de 1988 (1988). Brasília. Recuperado em 06 dezembro, 2017, de http://www.planalto.gov.br

/ccivil_03/constituicao/constituicao.htm

Creswell, J. W. (2012). Projeto de pesquisa: meatodos qualitativo, quantitativo e misto (M. Lopes, Trad.) (3a ed.) Porto Alegre: Artmed.

Decreto $n^{\circ}$ 1.171, de 22 de junho de 1994 (1994). Aprova o Código de Ética Profissional do Servidor Público Civil do Poder Executivo Federal. Recuperado em 27 abril, 2017, de http://www. planalto.gov.br/ccivil_03/decreto/d1171.htm 
Drumond, A. M., Silveira, S. F. R., \& Silva, E. A. (2014). Predominância ou coexistência? modelos de Administração Pública brasileira na Política Nacional de Habitação. Revista de Administração Pública, Rio de Janeiro 48(1), 325, janeiro/fevereiro.

Faoro, R. (1958). Os donos do poder: formação do patronato político brasileiro (vol 2, 9a ed.) São Paulo: Globo.

Gala, P. (2003). A teoria institucional de Douglass North. Revista de Economia Política, 23(2), abril/junho.

Gomes, N. F. (2014). Ética na Administração Pública: desafios e possibilidades. Revista de Administração Pública, Rio de Janeiro, 48(4), 1029-1050, julho/agosto.

Hegel, G. W. F. (1988). Principios de la filosofía del derecho. Barcelona: Edhasa.

Japiassú, H., \& Marcondes, D. (2008). Dicionário básico de filosofia (5a ed.) Rio de Janeiro: Zahar.

Kant, I. (1993). Fundamentos da metafísica dos costumes (L. Q. Henkel, Trad. p. 63) Rio de Janeiro: Ediouro.

Lakatos, E. M., \& Marconi, M. de A. (2017). Metodologia científica (7a ed.) São Paulo: Atlas.

Lipovetsky, G. (2005). A sociedade pós-moralista: o crepúsculo do dever e a ética indolor dos novos tempos democráticos (A. B. Ara, Trad.) Barueri: Manole.

Martins, G. A., \& Theóphilo, C. R. (2016). Metodologia da investigação científica para ciências sociais aplicadas (3a ed.) São Paulo: Atlas.

Matias-Pereira, J. (2008). Administração Pública comparada: uma avaliação das reformas administrativas no Brasil, EUA e União Europeia. Revista de Administração Pública, 42(1), 61-82, janeiro/fevereiro.

Maturana, H. R., \& Varela, F. (1995). A árvore do conhecimento: as bases biológicas do entendimento humano (J. P. Santos, Trad) Campinas: Editorial Psy II.

Melo, G. T., \& Helal, D. H. (2018). Estratégia e teoria institucional: convergências, divergências e perspectivas de pesquisa. Gestão Contemporânea, Porto Alegre, n. 15, janeiro/junho. Recuperado em 15 janeiro, 2018, de http://seer4.fapa.com.br/index.php

/arquivo/article/view/425

Mendes, A. V. C. (2014). A Administração Pública e o Sistema de Gestão da Ética: uma análise da política de promoção da ética no Poder Executivo Federal. Tese de Doutorado, Universidade de Brasília, Brasília, DF, Brasil.

Mendes, A. V. C., \& Andrade, H. Jr. (2010). Administração Pública Federal: a percepção dos servidores sobre a ética. Acta Scientiarum. Human and Social Sciences, Maringá, 32(2), 115-125.
Merleau-Ponty, M. (1999). Fenomenologia da percepção (2a ed.) São Paulo: Martins Fontes.

Morin, E. (2005). O método (vol 6). Porto Alegre: Sulina.

Nascimento, G. C., Rodrigues, V. J. R. J., \& Megliorini, E. (2010). Conceitos da teoria institucional: fonte propulsora de evolução para a gestão de desempenho. Anais do XVII Congresso Brasileiro de Custos, Belo Horizonte, MG, Brasil, 03 a 05 novembro. Recuperado em 02 fevereiro, 2018, de https://anaiscbc.emnuvens. com.br/anais/article/download/761/761

Nóbrega, T. P. da. (2008). Corpo, percepção e conhecimento em Merleau-Ponty. Estudos de Psicologia, 13(2), 141-148.

Novelino, M. (2014). Manual de Direito Constitucional (9a ed.) São Paulo: MÉTODO.

Organização para Cooperação e Desenvolvimento Econômico. (1998). Principles for managing ethics in the public service. Recuparado em 17 janeiro, 2018, de http: / / www.oecd.org/gov/

ethics/oecdprinciplesformanagingethicsinthepublicservi ce.htm

Peci, A. (2006). A nova teoria institucional em estudos organizacionais: uma abordagem crítica. Cadernos EBAPE. BR, 4(1), março.

Pereira, F. A. de M. (2012). A evolução da teoria institucional nos estudos organizacionais: um campo de pesquisa a ser explorado. Organizações em contexto, São Bernardo do Campo, 8(16), julho/dezembro.

Procopiuck, M. (2013). Poliaticas purblicas $e$ fundamentos da Administraçaロo Purblica: anarlise e avaliaçaロo, governança e redes de poliaticas, administraçaロo judiciarria. São Paulo: Atlas.

Rachels, J. (2006). Os elementos da filosofia da moral (R. Cavallari, Trad.) Barueri: Manole.

Ricoeur, P. (1991). O si-mesmo como um outro (L. M. César, Trad.) Campinas: PAPIRUS.

Rolnik, S. (1992). À sombra da cidadania: alteridade, homem da ética e reinvenção da democracia. Seção Ponto e Contraponto, Boletim de Novidades, Pulsional, Centro de Psicanálise, 5(41), 33-42. São Paulo, setembro.

Streck, L. L. (1999). Hermenêutica jurídica e(m) crise: uma exploração hermenêutica da construção do direito. Porto Alegre: Livraria do Advogado.

Taille. Y. de La. (2010). Moral e ética: uma leitura psicológica. Psicologia: teoria e pesquisa, 26(especial), 105-114.

Vieira, K. M., \& Dalmoro, M. (2008). Dilemas na 
Ética na Administração Pública: uma Análise da Percepção da Comunidade Universitária do

construção de escalas tipo likert: o número de itens e a disposição influenciam nos resultados? Anais do Encontro Nacional da Associação Nacional de Pós-Graduação $e$ Pesquisa em Administração, Rio de Janeiro, RJ, Brasil, 32, setembro. 